\title{
Clinical utility of ledipasvir/sofosbuvir in the treatment of adolescents and children with hepatitis $\mathrm{C}$
}

This article was published in the following Dove Press journal: Adolescent Health, Medicine and Therapeutics

\author{
Christine Hong Ting Yang' \\ Aparna Goel ${ }^{2}$ \\ Aijaz Ahmed ${ }^{2}$ \\ 'Division of Pediatric \\ Gastroenterology, Stanford University \\ School of Medicine, Stanford, CA, \\ USA; ${ }^{2}$ Division of Gastroenterology \\ and Hepatology, Stanford University \\ School of Medicine, Stanford, CA, USA
}

Correspondence: Aijaz Ahmed Division of Gastroenterology and Hepatology, Stanford University School of Medicine, 750 Welch Road, Suite \#210, Stanford, CA 94304, USA

$\mathrm{Tel}+\mathrm{I} 650498609$ I

Fax +l 6504985692

Email aijazahmed@stanford.edu

\begin{abstract}
Chronic infection with hepatitis $\mathrm{C}$ virus (HCV) affects an estimated $0.1 \%-2 \%$ of the pediatric population in the United States. While the clinical course in young children is indolent, adolescents who contract HCV have a disease course similar to adults, with a 26-fold increased risk of chronic liver disease-associated mortality, hepatocellular carcinoma, and need for curative liver transplantation. Furthermore, adolescent patients are entering childbearing age and carry a risk of passing $\mathrm{HCV}$ to their offspring via vertical transmission. Pegylated-interferon (PEG-IFN) with ribavirin was previously the only treatment option for pediatric patients with chronic hepatitis $\mathrm{C}(\mathrm{CHC})$, but the high likelihood of adverse reactions and subcutaneous route of administration limited its use and efficacy. Recently, the direct-acting antivirals (DAAs) ledipasvir (LDV) and sofosbuvir (SOF) were approved for adolescents with CHC. This review discusses the natural history of $\mathrm{CHC}$ in pediatric patients, data supporting LDV/SOF in adolescents, and ongoing studies evaluating DAAs in pediatric patients.
\end{abstract}

Keywords: hepatitis $\mathrm{C}$ virus, chronic hepatitis $\mathrm{C}$, adolescent, pediatric, direct-acting antivirals

\section{Introduction}

Hepatitis $\mathrm{C}$ virus (HCV) is an RNA virus that affects more than 180 million people worldwide. ${ }^{1}$ The HCV seroprevalence rate is $1 \%-1.5 \%$ in North America, with $0.17 \%$ in 6-11-year-olds and $0.39 \%$ in $12-19$-year-olds. HCV is the primary cause of chronic hepatitis of infectious etiology in children in industrialized countries ${ }^{2}$ and is estimated to affect $0.1 \%-2 \%$ of children in the United States. ${ }^{3}$ Chronic HCV infection (CHC) is defined by the presence of serum HCV RNA for at least 6 months after the onset of infection and includes the ensuing complications from liver injury that may develop. ${ }^{1}$ In the USA, it is estimated 23,000-46,000 children have $\mathrm{CHC},{ }^{4}$ and who are thus at risk for cirrhosis, hepatocellular carcinoma, and death. ${ }^{5}$

\section{HCV virology}

$\mathrm{HCV}$ is from the Flaviviridae family and hepacivirus genus and is a single-stranded, positive sense RNA virus. There are six genotypes, as well as 100 subtypes, which are denoted by lower-case letters. ${ }^{6}$ The six genotypes follow a geographic distribution. Genotype 1 is the most prevalent worldwide and accounts for the majority of HCV infections in North America (genotype 1a) and Europe (genotype1b). Genotype 2 is found in regions of Africa. Genotype 3 is commonly found in Asia, Europe, and Australia. Genotype 4 is mostly found in North Africa and the Middle East. Genotype 5 is found in Southern Sub-Saharan Africa. Lastly, genotype 6 is found mainly in 
Asia. ${ }^{2}$ Historically, genotype 3 has been considered the most challenging to treat. ${ }^{7}$

\section{Clinical course of $\mathrm{HCV}$ infection in pediatric patients}

The transmission of HCV is through blood contact. Before widespread blood screening efforts were established in 1992, transmission of HCV to pediatric patients occurred mostly through blood transfusions and organ transplantations. After 1992, vertical transmission has become the most common means of $\mathrm{HCV}$ transmission in children. ${ }^{8}$ Approximately 7,500 new cases of $\mathrm{CHC}$ occur annually in the US from vertical transmission. ${ }^{9}$ There is increasing concern for horizontal transmission through injection drug use, especially among adolescents. ${ }^{10} \mathrm{HCV}$ infection rates are rising among adolescents and young adults in the US, especially in eastern rural regions of the country. This is associated with the opioid epidemic and increased use of injected opiates. ${ }^{11}$ As these individuals are entering childbearing age, the risk of vertical transmission will also increase. ${ }^{12}$ Spontaneous clearance of infection occurs in $25 \%-40 \%$ of infected infants but occurs far less frequently in older children $(6 \%-12 \%){ }^{5}$ Thus, the majority of children (54\%-86\%) exposed to $\mathrm{HCV}$ will progress to develop $\mathrm{CHC}{ }^{2}$

For $\mathrm{CHC}$ acquired in childhood, the clinical course is indolent and usually asymptomatic. However, adolescents who acquire $\mathrm{CHC}$ have a clinical course similar to adults, ${ }^{13}$ with at 26-fold increased risk of liver-associated mortality, hepatocellular carcinoma, and need for liver transplantation, compared to age-matched controls. ${ }^{14,15}$ Additionally, the 10-year cost associated with pediatric HCV infection is estimated to be $\$ 199-336$ million $^{4}$ as pediatric patients with $\mathrm{CHC}$ have decreased quality of life from learning disorders, developmental delay, and cognitive deficits reflective of decreased executive function. ${ }^{16}$ Thus, it is critical to treat $\mathrm{HCV}$ infection in pediatric patients, in order to prevent progression of liver disease, development of hepatocellular carcinoma, transmission to subsequent generations, and to improve childhood development. ${ }^{17}$

\section{Medical therapy for pediatric patients with CHC}

Prior to 2017, the only US Food and Drug Administration (FDA) approved therapy for $\mathrm{CHC}$ in pediatric patients aged three and older was pegylated-interferon-alpha (PEG-IFN) given in combination with ribavirin. ${ }^{18}$ However, in 2017, both the European Medicines Agency (EMA) and the FDA approved the use of fixed-dose ledipasvir/sofosbuvir (LDV/ SOF) $90 \mathrm{mg} / 400 \mathrm{mg}$ once daily to treat adolescents (ages $12-17$ or weight $>35 \mathrm{~kg}$ ) with $\mathrm{CHC}$ with genotypes 1 and 4. Treatment duration is 12 weeks, unless patients have cirrhosis and previously failed therapy with PEG-IFN/ribavirin, in which case treatment duration is 24 weeks. Sofosbuvir with ribavirin is also approved to treat adolescents with $\mathrm{CHC}$ with genotypes 2 and 3 . For patients with genotype 2, treatment is SOF $400 \mathrm{mg}$ once daily with weight-based ribavirin $(15 \mathrm{mg} / \mathrm{kg}$ in two divided doses) for 12 weeks. For patients with genotype 3 , doses are the same but duration is 24 weeks (Table 1). ${ }^{10}$ There are ongoing trials for treatment with these agents for younger children. The current recommendation from the Hepatology Committee of the European Society of Pediatric Gastroenterology, Hepatology, and Nutrition (ESPGHAN) is to consider waiting until younger children are old enough to receive approved therapy, or use these medications off-label in young children with severe disease (Table 2). ${ }^{10}$

LDV and SOF are small molecules classified as directacting antivirals (DAAs). DAAs target a variety of viral enzymes, which are responsible for different parts of the HCV life cycle. The HCV genome encodes a precursor polyprotein, which is then processed by host peptidases and $\mathrm{HCV}$ proteases into structural (core, envelope E1, E2/p7) and non-structural (NS2: protease, NS3: protease, NS4A: NS3 cofactor, NS5A: involved in viral replication, NS5B: RNA polymerase) proteins. ${ }^{19,20}$ DAAs attack non-structural proteins, and are classified based on the non-structural proteins they inhibit.

LDV is an NS5A inhibitor and SOF is an NS5B nucleoside analog polymerase inhibitor. NS5A is an RNA binding

Table I Drugs approved by the EMA and FDA for the treatment of children with CHC

\begin{tabular}{llll}
\hline Drug & Age (years) & HCV genotype & Dose \\
\hline Ledipasvir/sofosbuvir & $12-17$ & $\mathrm{I}, 4,5,6$ & $90 / 400 \mathrm{mg}$ PO daily \\
Sofosbuvir & $12-17$ & 2,3 & $400 \mathrm{mg}$ PO daily \\
Ribavirin & $\mathrm{I}-18$ & $\mathrm{I}-6$ & $15 \mathrm{mg} / \mathrm{kg}$ PO daily divided in two doses \\
Interferon $\alpha-2 \mathrm{~b}$ & $3-18$ & $\mathrm{I}-6$ & $\mathrm{six} \times 10^{6} \mathrm{IU} / \mathrm{m}^{2} \mathrm{SQ}$ three times weekly \\
Pegylated interferon $\alpha-2 \mathrm{~b}$ & $3-18$ & $\mathrm{I}-6$ & $1.5 \mathrm{mg} / \mathrm{kg}$ SQ once weekly \\
Pegylated interferon $\alpha-2 \mathrm{a}$ & $5-18$ & $\mathrm{I}-6$ & $100 \mathrm{mg} / \mathrm{m}^{2}$ SQ once weekly \\
\hline
\end{tabular}

Abbreviations: CHC, chronic hepatitis C; EMA, European Medicines Agency; FDA, US Food and Drug Administration; HCV, hepatitis C virus; PO, per os; SQ, subcutaneous. 
Table 2 Current recommendations from ESPGHAN's hepatology committee for the treatment of CHC in adolescents (children $>$ I2 years or weight $>35 \mathrm{~kg}$ )

\begin{tabular}{|c|c|}
\hline Recommendation & $\begin{array}{l}\text { Quality of evidence and strength of } \\
\text { recommendation per GRADE system }\end{array}$ \\
\hline HCV genotypes I and 4 should be treated with LDV/SOF $90 / 400 \mathrm{mg}$ once daily for 12 weeks & $\mathrm{Cl}$ \\
\hline HCV genotype I with cirrhosis should be treated with LDV/SOF $90 / 400 \mathrm{mg}$ once daily for 24 weeks & $\mathrm{C} 2$ \\
\hline $\begin{array}{l}\mathrm{HCV} \text { genotype } 2 \text { should be treated with SOF } 400 \mathrm{mg} \text { once daily and weight-based ribavirin ( } 15 \mathrm{mg} / \mathrm{kg} \\
\text { in two divided doses) for } 12 \text { weeks }\end{array}$ & $\mathrm{Cl}$ \\
\hline $\begin{array}{l}\mathrm{HCV} \text { genotype } 3 \text { should be treated with SOF } 400 \mathrm{mg} \text { once daily and weight-based ribavirin ( } 15 \mathrm{mg} / \mathrm{kg} \\
\text { in two divided doses) for } 24 \text { weeks }\end{array}$ & $\mathrm{Cl}$ \\
\hline $\begin{array}{l}\text { IFN-free regimens are the best options for HCV-infected adolescents, regardless of liver disease } \\
\text { stage and co-morbidities, and PEG-IFN with ribavirin is no longer recommended as of } 2017 \text { for the } \\
\text { treatment of HCV in adolescents }\end{array}$ & $\mathrm{Cl}$ \\
\hline
\end{tabular}

protein involved in viral assembly. ${ }^{21,22}$ NS5A inhibitor monotherapy was found to be effective in decreasing HCV RNA, but viral resistance to NS5A monotherapy quickly developed. ${ }^{23}$ Hence, NS5A inhibitors are used in combination with other agents. ${ }^{24}$ NS5B is an RNA-dependent polymerase, ${ }^{25}$ and inhibitors of NS5B are labeled either as nucleoside analog inhibitors (these are incorporated into RNA to cause termination) or non-nucleoside inhibitors (these bind to allosteric sites and cause conformational change in RNA polymerase). ${ }^{26}$ As NS5B nucleoside analog inhibitors inhibit a highly conserved region among genotypes, this gives them broad activity against many genotypes. It is also difficult for HCV to develop mutations to resist NS5B inhibitors, as mutations in the viral RNA polymerase result in loss of function. ${ }^{25}$

\section{LDV/SOF use in adults}

The introduction of DAAs in 2011 revolutionized CHC treatment in adults, and nowadays $\mathrm{CHC}$ in adults is considered curable. There are currently ten different oral regimens licensed by the EMA and FDA for treatment of $\mathrm{CHC}$ in adults. All regimens achieve high ( $>90 \%)$ sustained virologic response (SVR) rates with 12 weeks of therapy, regardless of genotype, stage of fibrosis, or presence of human immunodeficiency virus (HIV) infection. SVR is defined as undetectable HCV RNA after completion of therapy, usually evaluated 12 weeks after treatment completion and coined "SVR12". Certain populations can even achieve equally high SVR rates with only 8 weeks of therapy. ${ }^{27}$

The efficacy of LDV/SOF in treating adults with CHC genotype 1 was established in multiple Phase III trials, including ION- $1,{ }^{28}-2,{ }^{29}$ and $-3,{ }^{27}$ along with a Japanese Phase III trial. ${ }^{30}$ The oral, once daily fixed dose pill of LDV/SOF
$90 \mathrm{mg} / 400 \mathrm{mg}$ was used in all four trials that ranged from 341 to 865 patients. These trials found SVR12 rates of $\geq 93 \%$ in both treatment-naïve and treatment-experienced patients, regardless of treatment duration $(8,12$, or 24 weeks), as well as whether it was administered with or without ribavirin. Rates of virologic breakthrough (reappearance of HCV RNA while on therapy) or relapse (reappearance of HCV RNA after completion of therapy) were low in all four studies, ranging from $0 \%-6 \%$. ${ }^{31}$ These findings have been corroborated in several large real-world observational and registry studies ranging from 600 to 14,000 patients. ${ }^{32-40}$ The efficacy of LDV/ SOF for treating adults with CHC from other genotypes has also been supported by multiple Phase II trials, ${ }^{41-47}$ a Japanese Phase III trial, and real-world data from a French cohort. ${ }^{31}$

LDV/SOF has shown great safety and in treatment-naïve and treatment-experienced adult patients with $\mathrm{CHC}$ with all genotypes. Pooled analysis of the ION trials found that treatment-emergent adverse events (TEAEs) occurred in $74 \%$ of $1,080 \mathrm{LDV} / \mathrm{SOF}$ patients, and $85 \%$ of LDV/SOF with ribavirin patients, with most TEAEs mild to moderate in severity. ${ }^{48}$ Very few $(0 \%-2 \%)$ of patients discontinued treatment due to TEAEs. The most common treatment-related adverse events (TRAEs) were fatigue (13\%-18\%), headache $(11 \%-17 \%)$, nausea $(6 \%-9 \%)$, diarrhea $(3 \%-7 \%)$, and insomnia $(3 \%-6 \%)$, most of which were grade 1 in severity. ${ }^{31}$ Treatment-emergent serious adverse events (SAEs) occurred in $2 \%$ of LDV/SOF patients and $3 \%$ of LDV/SOF with ribavirin patients; of these, $\leq 0.4 \%$ were considered treatment-related. ${ }^{48}$

\section{LDVISOF use in adolescents}

In children, SVR24 (sustained virologic response 24 weeks after completion of therapy) corresponds to definitive cure 
in $98 \%-100 \%$ of cases. ${ }^{49,50}$ With the successful use of DAAs in adults with $\mathrm{CHC}$, there is now great interest in their use in children. In the US, there are currently eight clinical trials evaluating DAAs in pediatric patients (Table 3 ). ${ }^{10}$

Data from a Phase II, multicenter open-label study (NCT 02249182) evaluating safety and efficacy of LDV/SOF in 100 adolescent patients aged 12-17 years with CHC genotype 1 showed an excellent SVR rate of $98 \% .{ }^{11}$ In this study, patients received fixed-dose LDV/SOF $90 \mathrm{mg} / 400 \mathrm{mg}$ once daily for 12 weeks. Patient demographics were: $37 \%$ were males and $63 \%$ were females, $90 \%$ were white, and average weight was $61 \mathrm{~kg}$ (range $33-126 \mathrm{~kg}$ ). HCV history was: average baseline HCV RNA $\log _{10}$ IU/mL 6.0 (range 4.7-7.0) with 55\% having HCV RNA > 800,000 IU/mL, 81\% genotype 1a, $80 \%$ treatment-naïve, $1 \%$ with cirrhosis, and $84 \%$ infected through vertical transmission. Pharmacokinetic evaluation of LDV, SOF, and the SOF metabolite GS-331007 was comparable to those of adult patients receiving the same dose in Phase II and III trials. The primary efficacy endpoint was percentage of patients achieving SVR12, which occurred in 98/100 (98\%) patients, including the one patient with cirrhosis. The two patients in which SVR12 was not achieved were lost to follow-up either during or after treatment, but both had undetectable viral loads at the time of their last visit. None of the 98 patients achieving SVR experienced virologic breakthrough or relapse. Adverse reactions were similar to the adult population, including headache $(27 \%)$, diarrhea $(14 \%)$, and fatigue (13\%), with no serious adverse events or treatment discontinuation reported. Nine patients developed transient grade 3-4 (severe or life threatening) laboratory abnormalities which later resolved after treatment completion. There was no effect on child development through the 12 weeks of follow-up as evaluated by Tanner staging. ${ }^{11}$ Quality of life was also found to improve significantly both during and after treatment. ${ }^{17}$ Currently, follow-up to evaluate for SVR24 after treatment is in process, ${ }^{51}$ as are studies in other age groups
(3-11 years) and genotypes (4, 5, and 6). Estimated date of study completion is July $2018 .{ }^{10}$

A prospective, multicenter open-label study in Egypt of 144 adolescents (mean age 14 years, range 12-16 years, $69 \%$ males) with $\mathrm{CHC}$ with genotype 4 treated with fixed dose LDV/SOF $90 \mathrm{mg} / 400 \mathrm{mg}$ once daily for 12 weeks also showed promising results. ${ }^{14}$ In this cohort, 128/144 (89\%) were treatment-naïve with mean baseline $\mathrm{HCV}$ RNA $\log _{10}$ IU/mL 5.26 (range 3.70-6.73). Transient elastography measurements revealed 96/144 (67\%) had F0/F1 fibrosis, 48/144 (33\%) had F2 fibrosis, and there were no patients with F3-4 fibrosis or cirrhosis. Virologic monitoring was performed before treatment, at weeks 4 and 12 of treatment, and 12 weeks after treatment. SVR12 was achieved in 142/144 (99\%) of patients. The two patients that did not achieve SVR12 were treatment naïve and had early virologic response to LDV/ SOF but relapsed. No serious adverse events were observed, and no patients discontinued therapy due to adverse events. Headache was the most common side effect (20\%), and treatment-experienced patients had significantly higher rates of pruritus $(31 \%, P=0.007)$, diarrhea $(44 \%, P<0.001)$, and rash $(19 \%, P=0.002)$ compared to treatment-naïve patients. One treatment-naïve patient developed hyperbilirubinemia and anemia, and one treatment-experienced patient developed anemia. Both of these laboratory abnormalities resolved after the end of treatment. ${ }^{14}$

\section{Other published DAA data in adolescents SOF and ribavirin use in adolescents}

Data from a Phase II, multicenter, open-label study (NCT 02175758) evaluating safety and efficacy of SOF with ribavirin in 52 patients aged $12-17$ years (median age 15 years) with $\mathrm{CHC}$ with genotype 2 or 3 also showed promising results. ${ }^{52}$ Thirteen patients genotype $2(25 \%)$ and 39 with genotype $3(75 \%)$ infection were recruited from 30 study sites

Table 3 Clinical trials evaluating DAA use in pediatric patients with $\mathrm{CHC}$

\begin{tabular}{|c|c|c|c|}
\hline Drug & HCV genotype & Study identifier & Estimated completion \\
\hline Glecaprevir/pibrentasvir & $1-6$ & NCT 03067129 & May 2022 \\
\hline Gratisovir + ribavirin & $1-6$ & NCT 02486406 & June 2018 \\
\hline Ledipasvir/sofosbuvir & $\mathrm{I}, 4$ & NCT 02868242 & April 2019 \\
\hline Ledipasvir/sofosbuvir \pm ribavirin & $1,4,5,6$ & NCT 02249182 & July 2018 \\
\hline Ombitasvir/paritaprevir/ritonavir \pm dasabuvir \pm ribavirin & $\mathrm{I}, 4$ & NCT 02486406 & September 2019 \\
\hline Sofosbuvir + daclatasvir & 4 & NCT 03080415 & June 2018 \\
\hline Sofosbuvir + ribavirin & 2,3 & NCT 021755758 & April 2018 \\
\hline Sofosbuvir/velpatasvir & $1-6$ & NCT 0302298I & December 2019 \\
\hline
\end{tabular}

Abbreviations: $\mathrm{CHC}$, chronic hepatitis C; DAA, direct-acting antivirals; $\mathrm{HCV}$, hepatitis $\mathrm{C}$ virus. 
in Australia, Germany, Italy, New Zealand, Russia, the UK, and the US. Most patients (43/52, 83\%) were treatment-naïve, $60 \%(31 / 52)$ were male, and $90 \%$ (47/52) were white. No patients had known cirrhosis; 21/52 (40\%) were documented as not having cirrhosis, and the remainder were not assessed for presence or absence of cirrhosis. All received SOF $400 \mathrm{mg}$ once daily, and weight-based ribavirin $(15 \mathrm{mg} / \mathrm{kg}$ divided into two doses), either for 12 weeks (genotype 2) or 24 weeks (genotype 3 ). ${ }^{52}$ The adult dose of SOF $400 \mathrm{mg}$ was given as pharmacokinetic results showed similar plasma exposure and safety profiles. ${ }^{53}$ Pharmacokinetic studies for SOF and GS-331007 were also done at day seven in the first 10 patients enrolled, as well as with sparse sampling throughout treatment, and were found to be comparable to prior SOF studies with adults. The primary efficacy endpoint was the percentage of patients achieving SVR12, which was achieved in $98 \%$ $(51 / 52)$ of patients. The single patient who did not achieve SVR12 had HCV genotype 3 and was lost to follow-up after 4 weeks of treatment during which the viral load was already undetectable. The most common adverse events were nausea (27\%) and headache (23\%), and no patients discontinued treatment due to adverse events. Only one patient reported a grade 3 (severe) adverse event, which was a shoulder joint injury that was not considered related to the study drug. ${ }^{52}$ The study is ongoing in younger children. The dose of SOF for patients aged 6-11 will be $200 \mathrm{mg}$. This dosing is from pharmacokinetic data in adults, along with a lead-in group of patients in the 6-11 age group. ${ }^{54}$ Pharmacokinetic lead-in results for patients aged 3-5 are pending.

In addition, there is an ongoing study Phase II/III in Egypt evaluating the safety and efficacy of gratisovir (a generic of sofosbuvir) and ribavirin in pediatric patients with $\mathrm{CHC}$ 10-18 years in age (NCT 02985281). ${ }^{55}$ Generic versions of sofosbuvir have been studied in adults with $\mathrm{CHC}$ genotype 4 in Egypt. One study found no significant difference in SVR12 rates between patients treated with ribavirin and either gratisovir or grateziano, which are both generic versions of sofosbuvir. ${ }^{56}$ Another study found that dual gratisovir/ daclatasvir treatment duration tailored according to vRVR at 8 or 12 weeks was non-inferior compared to a fixed 12-week treatment duration. ${ }^{27}$

\section{Sofosbuvir and daclatasvir use in adolescents}

Sofosbuvir and daclatasvir therapy for 12 weeks is an option for the treatment of CHC (all genotypes) in adults. ${ }^{57}$ Furthermore, a study in adults who achieved very rapid virologic response (vRVR, defined as undetectable serum HCV RNA by week 2 of treatment) showed that decreasing the duration of therapy to 8 weeks was non-inferior to the standard 12-week treatment course. ${ }^{27}$ In adolescents, there has been a pilot study of a cohort of 10 adolescents from Egypt with $\mathrm{CHC}$ from any genotype treated with SOF and daclatasvir. ${ }^{58}$ The first ten consecutive adolescent patients who fulfilled eligibility criteria were treated with weight-based SOF and weight-based daclatasvir; as all patients weighed $>40$ $\mathrm{kg}$, they all received the adult doses of $400 \mathrm{mg}$ and $60 \mathrm{mg}$ once daily, respectively. All achieved vRVR at week 2, thus all received 8 weeks of treatment instead of 12 weeks. All patients completed 8 weeks of treatment, and SVR12 was achieved in all patients. Six patients reported adverse events, including nausea, abdominal pain, fatigue, and headache; all were mild to moderate in severity. ${ }^{58}$

\section{LDV/SOF use in children}

There is preliminary data from 90 children (aged 6-11 years) treated with SOF/LDV $45 \mathrm{mg} / 200 \mathrm{mg}$, with or without ribavirin. ${ }^{59}$ Of the 90 children, there were 86,3 , and 2 with genotypes 1, 3, and 4 respectively; $59 \%$ were male, $79 \%$ were whites, and $80 \%$ were treatment-naïve. Median age was 9 years, median weight was $33 \mathrm{~kg}$, and median BMI was $18 \mathrm{~kg} / \mathrm{m}^{2}$. Pharmacokinetic evaluation was done on day 10 in the first 12 participants, and found that LDV, SOF, and GS-331007 exposures were equivalent to those in adults. At the time of this review, 88/90 patients had completed therapy, and the rate of SVR at 4 weeks post-treatment (SVR4) in these 88 patients was $99 \%(87 / 88)$; one genotype 1a patient relapsed at 12 weeks of LDV/SOF therapy. No patients experienced grade 3 or 4 adverse events, and the only serious adverse events reported were a tooth abscess, abdominal pain, and gastroenteritis not believed to be related to the study drug. The most common adverse events were abdominal pain, headache, diarrhea, vomiting, nausea, fatigue, fever, cough, and oropharyngeal pain. ${ }^{60}$

\section{Ongoing DAA trials for pangenotype $\mathrm{CHC}$ in pediatric patients}

Of the ongoing clinical trials evaluating DAAs in pediatric patients with $\mathrm{CHC}$, there are two which are evaluating $\mathrm{CHC}$ from all genotypes: sofosbuvir/velpatasvir and glecaprevir/ pibrentasvir.

\section{Sofosbuvir/velpatasvir (SOF/VEL)}

Velpatasvir (VEL) is an NS5A inhibitor and is given with SOF as a single-tablet combination DAA. This was the first 
single-tablet pangenotype DAA therapy for CHC. In adults, SVR12 rates range between $95 \%$ and $100 \%$ in a variety of populations, including those with compensated cirrhosis and prior treatment failures. Duration of treatment is 12 weeks, regardless of genotype, prior treatment, cirrhosis, or presence of NS5A-resistant mutations. Patients with uncompensated cirrhosis are also treated with ribavirin. Adverse reactions include fatigue, headache, nausea, and nasopharyngitis, but it is overall well tolerated. ${ }^{61}$ The pediatric clinical trial (NCT03022981) is ongoing and is a Phase II trial with two parts: pharmacokinetics lead-in phase and treatment phase. The pharmacokinetic phase will evaluate pediatric SOF/VEL dosing; the treatment phase will evaluate safety and efficacy of a 12-week course of treatment. Patients will be divided into three cohorts for the pharmacokinetic phase (ages 12 to $<18,6$ to $<12$, and 3 to $<6$ years), and two cohorts for the treatment phase (ages 12 to $<18$, and 3 to $<12$ years). Estimated enrollment is 200 patients, with estimated primary completion date December 2019. ${ }^{62}$

\section{Glecaprevir/pibrentasvir (GLE/PIB)}

Glecaprevir is an NS3/4A protease inhibitor, and pibrentasvir (PIB) is an NS5A inhibitor. GLE/PIB is effective across all $\mathrm{HCV}$ genotypes, including in patients with chronic kidney disease (as it is minimally excreted by the kidneys), HIV infection, and compensated cirrhosis, as well as those who have failed a previous NS5A treatment regimen. In addition, treatment duration is shortened to 8 weeks in treatmentnaïve patients without cirrhosis. ${ }^{63,64}$ The pediatric clinical trial (NCT03067129) is a Phase III trial evaluating the pharmacokinetics, safety, and efficacy of GLE/PIB. Patients will be divided into four age groups: 12 to $<18,9$ to $<12$, 6 to $<9$, and 3 to $<6$ years. Some patients in all age groups will undergo pharmacokinetic evaluation to determine the pharmacokinetics of GLE/PIB in each age group, with the rest undergoing evaluation of safety and efficacy of GLE/ PIB. Estimated enrollment is 110 patients, with estimated primary completion date September $2019 .{ }^{65}$

\section{Conclusion}

The development of DAAs has dramatically changed the landscape of HCV treatment in adults with $\mathrm{CHC}$. LDV/ SOF and SOF with ribavirin are now approved treatments for adolescents with $\mathrm{CHC}$. There are few published studies examining DAAs in the pediatric population, and none with long-term follow-up. Furthermore, currently there is no data from controlled trials regarding DAA use in children with coinfections (such as hepatitis B virus or HIV), co-morbidities, or those who are nonsustained virological responders to DAAs. ${ }^{10}$ However, the results of DAAs in the adult population are encouraging for their expanded use in the younger population, and there have been promising cases of children successfully treated with DAAs who had cirrhosis. ${ }^{10,66,67}$ There are several ongoing clinical trials evaluating LDV/SOF and SOF with ribavirin in younger children. It is anticipated that more treatment options will become available to treat $\mathrm{CHC}$ in pediatric patients in the upcoming years.

\section{Disclosure}

Aijaz Ahmed is a consultant and advisory board member for AbbVie Pharmaceuticals, Gilead Sciences, and Janssen Pharmaceutical. Aijaz Ahmed has research funding/grant from Gilead Sciences. The authors report no other conflicts of interest in this work.

\section{References}

1. Mack CL, Gonzalez-Peralta RP, Gupta N, et al. NASPGHAN practice guidelines: diagnosis and management of hepatitis $\mathrm{C}$ infection in infants, children, and adolescents. $J$ Pediatr Gastroenterol Nutr. 2012;54(6):838-855.

2. El-Shabrawi MH, Kamal NM. Burden of pediatric hepatitis C. World J Gastroenterol. 2013;19(44):7880-7888.

3. Armstrong GL, Wasley A, Simard EP, Mcquillan GM, Kuhnert WL, Alter MJ. The prevalence of hepatitis C virus infection in the United States, 1999 through 2002. Annu Int Med. 2006;144:705-714.

4. Jhaveri R, Grant W, Kauf TL, Mchutchison J. The burden of hepatitis C virus infection in children: estimated direct medical costs over a 10 -year period. J Pediatr. 2006;148(3):353-358.

5. Pham YH, Rosenthal P. Chronic hepatitis C infection in children. $A d v$ Pediatr. 2016;63(1):173-194.

6. Slowik MK, Jhaveri R. Hepatitis B and C viruses in infants and young children. Semin Pediatr Infect Dis. 2005;16(4):296-305.

7. Goossens N, Negro F. Is genotype 3 of the hepatitis $C$ virus the new villain? Hepatology. 2014;59(6):2403-2412.

8. Serranti D, Buonsenso D, Ceccarelli M, Gargiullo L, Ranno O, Valentini P. Pediatric hepatitis $C$ infection: to treat or not to treat ... what's the best for the child? Eur Rev Med Pharmacol Sci. 2011;15(9):1057-1067.

9. Omland LH, Krarup H, Jepsen P, et al. Mortality in patients with chronic and cleared hepatitis $\mathrm{C}$ viral infection: a nationwide cohort study. J Hepatology. 2010;53(1):36-42.

10. Indolfi G, Hierro L, Dezsofi A, et al. Treatment of chronic hepatitis C virus infection in children: a position paper by the Hepatology Committee of European Society of Paediatric Gastroenterology, Hepatology and Nutrition. J Pediatr Gastroenterol Nutr. 2018;66(3):505-515.

11. Balistreri WF, Murray KF, Rosenthal P, et al. The safety and effectiveness of ledipasvir-sofosbuvir in adolescents $12-17$ years old with hepatitis C virus genotype 1 infection. Hepatology. 2017;66(2):371-378.

12. Koneru A, Nelson N, Hariri S, et al. Increased hepatitis C virus (HCV) detection in women of childbearing age and potential risk for vertical transmission - United States and Kentucky, 2011-2014. MMWR Morb Mortal Wkly Rep. 2016;65(28):705-710.

13. Baker RD, Baker SS. Hepatitis $\mathrm{C}$ in children in times of change. Current Opinion Pediatrics. 2015;271-5.

14. El-Khayat HR, Kamal EM, El-Sayed MH, et al. The effectiveness and safety of ledipasvir plus sofosbuvir in adolescents with chronic hepatitis $\mathrm{C}$ virus genotype 4 infection: a real-world experience. Aliment Pharmacol Ther. 2018;47(6):838-844. 
15. Omland LH, Krarup H, Jepsen P, et al. Mortality in patients with chronic and cleared hepatitis $\mathrm{C}$ viral infection: a nationwide cohort study. J Hepatol. 2010;53(1):36-42.

16. Rodrigue JR, Balistreri W, Haber B, et al. Impact of hepatitis C virus infection on children and their caregivers: quality of life, cognitive, and emotional outcomes. J Pediatr Gastroenterol Nutr. 2009;48(3):341-347.

17. Younossi ZM, Stepanova M, Balistreri W, et al. Health-related quality of life in adolescent patients with hepatitis $\mathrm{C}$ genotype 1 treated with sofosbuvir and ledipasvir. J Pediatr Gastroenterol Nutr. 2018;66(1) $112-116$.

18. Ghany MG, Strader DB, Thomas DL, Seeff LB, American Association for the Study of Liver Diseases, Aaftsol D. Diagnosis, management, and treatment of hepatitis C: an update. Hepatology. 2009;49(4):1335-1374.

19. Kanda T, Steele R, Ray R, Ray RB. Small interfering RNA targeted to hepatitis $\mathrm{C}$ virus 5' nontranslated region exerts potent antiviral effect J Virol. 2007;81(2):669-676.

20. Moradpour D, Penin F. Hepatitis C virus proteins: from structure to function. Curr Top Microbiol Immunol. 2013;369:113-142.

21. Kohler JJ, Nettles JH, Amblard F, et al. Approaches to hepatitis C treatment and cure using NS5A inhibitors. Infect Drug Resist. 2014;7:41-56.

22. Fridell RA, Qiu D, Valera L, Wang C, Rose RE, Gao M. Distinct functions of NS5A in hepatitis C virus RNA replication uncovered by studies with the NS5A inhibitor BMS-790052. J Virol. 2011;85(14): 7312-7320.

23. Nettles RE, Gao M, Bifano M, et al. Multiple ascending dose study of BMS-790052, a nonstructural protein 5A replication complex inhibitor, in patients infected with hepatitis $\mathrm{C}$ virus genotype 1. Hepatology. 2011;54(6):1956-1965.

24. Lee C. Daclatasvir: potential role in hepatitis C. Drug Des Devel Ther 2013;7:1223-1233.

25. Serranti D, Indolfi G, Resti M. New treatments for chronic hepatitis C: an overview for paediatricians. World $J$ Gastroenterol. 2014;20(43):15965-15974.

26. Koch U, Narjes F. Allosteric inhibition of the hepatitis $C$ virus NS5B RNA dependent RNA polymerase. Infect Disord Drug Targets. 2006;6(1):31-41.

27. Yakoot M, Abdo AM, Abdel-Rehim S, Helmy S. Response tailored protocol versus the fixed 12 weeks course of dual sofosbuvir/daclatasvir treatment in Egyptian patients with chronic hepatitis C genotype-4 infection: a randomized, open-label, non-inferiority trial. EBioMedicine. 2017;21:182-187.

28. Afdhal N, Zeuzem S, Kwo P, et al. Ledipasvir and sofosbuvir for untreated HCV genotype 1 infection. N Engl J Med. 2014;370(20):1889-1898.

29. Afdhal N, Reddy KR, Nelson DR, et al. Ledipasvir and sofosbuvir for previously treated HCV genotype 1 infection. $N$ Engl J Med. 2014;370(16):1483-1493.

30. Mizokami M, Yokosuka O, Takehara T, et al. Ledipasvir and sofosbuvir fixed-dose combination with and without ribavirin for 12 weeks in treatment-naive and previously treated Japanese patients with genotype 1 hepatitis C: an open-label, randomised, phase 3 trial. Lancet Infect Dis. 2015;15(6):645-653.

31. Scott LJ. Ledipasvir/sofosbuvir: a review in chronic hepatitis C. Drugs. 2018;78(2):245-256.

32. Kowdley KV, Sundaram V, Jeon CY, et al. Eight weeks of ledipasvir/ sofosbuvir is effective for selected patients with genotype 1 hepatitis C virus infection. Hepatology. 2017;65(4):1094-1103.

33. Butt AA, Yan P, Shaikh OS, Chung RT, Sherman KE, ERCHIVES study, Study E. Treatment adherence and virological response rates in hepatitis $C$ virus infected persons treated with sofosbuvir-based regimens: results from ERCHIVES. Liver Int. 2016;36(9):1275-1283.

34. Terrault NA, Zeuzem S, di Bisceglie AM, et al. Effectiveness of ledipasvir-sofosbuvir combination in patients with hepatitis $\mathrm{C}$ virus infection and factors associated with sustained virologic response. Gastroenterology. 2016;1511140(6):1131.

35. Tapper EB, Bacon BR, Curry MP, et al. Real-world effectiveness for 12 weeks of ledipasvir-sofosbuvir for genotype 1 hepatitis $\mathrm{C}$ : the Trio Health study. J Viral Hepat. 2017;24(1):22-27.
36. Tapper EB, Bacon BR, Curry MP, et al. Evaluation of proton pump inhibitor use on treatment outcomes with ledipasvir and sofosbuvir in a real-world cohort study. Hepatology. 2016;64(6):1893-1899.

37. Curry MP, Tapper EB, Bacon B, et al. Effectiveness of 8- or 12-weeks of ledipasvir and sofosbuvir in real-world treatment-naïve, genotype 1 hepatitis C infected patients. Aliment Pharmacol Ther. 2017;46(5):540-548.

38. Backus LI, Belperio PS, Shahoumian TA, Loomis TP, Mole LA. Real-world effectiveness of ledipasvir/sofosbuvir in 4,365 treatment-naive, genotype 1 hepatitis C-infected patients. Hepatology. 2016;64(2):405-414.

39. Backus LI, Belperio PS, Shahoumian TA, Loomis TP, Mole LA. Comparative effectiveness of ledipasvir/sofosbuvir \pm ribavirin vs. ombitasvir/paritaprevir/ritonavir+dasabuvir \pm ribavirin in 6961 genotype 1 patients treated in routine medical practice. Aliment Pharmacol Ther. 2016;44(4):400-410.

40. Backus LI, Belperio PS, Shahoumian TA, Loomis TP, Mole LA. Realworld effectiveness and predictors of sustained virological response with all-oral therapy in 21,242 hepatitis C genotype-1 patients. Antivir Ther. 2017;22(6):481-493.

41. Gane EJ, Hyland RH, Yang Y, et al. Efficacy of ledipasvir plus sofosbuvir for 8 or 12 weeks inpatients with hepatitis C virus genotype 2 infection. Gastroenterology. 2017;152(6):1366-1371.

42. Feld JJ, Ramji A, Shafran SD, et al. Ledipasvir-sofosbuvir plus ribavirin in treatment-naive patients with hepatitis $C$ virus genotype 3 infection: an open-label study. Clin Infect Dis. 2017;65(1):13-19.

43. Gane EJ, Hyland RH, An D, et al. Efficacy of ledipasvir and sofosbuvir, with or without ribavirin, for 12 weeks in patients with HCV genotype 3 or 6 infection. Gastroenterology. 2015;1491461(6):1454-1461.

44. Abergel A, Metivier S, Samuel D, et al. Ledipasvir plus sofosbuvir for 12 weeks in patients with hepatitis $\mathrm{C}$ genotype 4 infection. Hepatology. 2016;64(4):1049-1056.

45. Kohli A, Kapoor R, Sims Z, et al. Ledipasvir and sofosbuvir for hepatitis $\mathrm{C}$ genotype 4: a proof-of-concept, single-centre, open-label phase $2 \mathrm{a}$ cohort study. Lancet Infect Dis. 2015;15(9):1049-1054.

46. Abergel A, Asselah T, Metivier S, et al. Ledipasvir-sofosbuvir in patients with hepatitis $\mathrm{C}$ virus genotype 5 infection: an open-label, multicentre, single-arm, phase 2 study. Lancet Infect Dis. 2016;16(4):459-464.

47. Nguyen MH, Trinh H, do S, Nguyen T, Nguyen P, Henry L. Open label study of 8 vs. 12 weeks of ledipasvir/sofosbuvir in genotype 6 treatment naïve or experienced patients. Am J Gastroenterol. 2017;112(12): 1824-1831.

48. Alqahtani SA, Afdhal N, Zeuzem S, et al. Safety and tolerability of ledipasvir/sofosbuvir with and without ribavirin in patients with chronic hepatitis C virus genotype 1 infection: Analysis of phase III ION trials. Hepatology. 2015;62(1):25-30.

49. Haber B, Alonso E, Pedreira A, et al. Long-term follow-up of children treated with peginterferon and ribavirin for hepatitis $\mathrm{C}$ virus infection. J Pediatr Gastroenterol Nutr. 2017;64(1):89-94.

50. Kelly DA, Haber B, González-Peralta RP, et al. Durability of sustained response shown in paediatric patients with chronic hepatitis $\mathrm{C}$ who were treated with interferon alfa-2b plus ribavirin. J Viral Hepat. 2012;19(4):263-270.

51. Balisteri W, Rosenthal P, Bansal S, et al. Ledipasvir/sofosbuvir for 12 weeks is safe and effective in adolescents with chronic hepatitis C infection. J Pediatr Gastroenterol Nutr. 2016;63(Suppl. 2):S140-141.

52. Wirth S, Rosenthal P, Gonzalez-Peralta RP, et al. Sofosbuvir and ribavirin in adolescents $12-17$ years old with hepatitis $C$ virus genotype 2 or 3 infection. Hepatology. 2017;66(4):1102-1110.

53. Kirby B. Adult Doses of Sofosbuvir Plus Ribavirin or Ledipasvir/ Sofosbuvir Provided Comparable Plasma Exposures and Tolerable Safety Profile in Adolescents with Hepatitis C Virus (HCV) Infection. San Francisco, CA: American Association for the Study of Liver Disease Annual Meeting; November 13-17, 2015.

54. Garrison KL, Mathias A, Kersey K, et al. Pharmacokinetics of oncedaily sofosbuvir and ledipasvir/sofosbuvir in $\mathrm{HCV}$-infected pediatrics aged 6 to $<12$ years old. Paper presented at: The Liver Meeting 2016; Boston, MA 
55. Squires JE, Balistreri WF. Hepatitis $C$ virus infection in children and adolescents. Hepatol Commun. 2017;1(2):87-98.

56. Yakoot M, Abdo AM, Yousry A, Helmy S. Very rapid virologic response and early $\mathrm{HCV}$ response kinetics, as quick measures to compare efficacy and guide a personalized response-guided therapy. Drug Des Devel Ther. 2016;10:2659-2667.

57. European Association for the Study of the Liver. Electronic address easloffice@easloffice.eu. EASL recommendations on treatment of hepatitis C 2016. J Hepatol. 2017;66(1):153-194.

58. El-Shabrawi MH, Abdo AM, El-Khayat HR, Yakoot M. Shortened 8 weeks course of dual sofosbuvir/daclatasvir therapy in adolescent patients, with chronic hepatitis C infection. J Pediatr Gastroenterol Nutr. 2018;66(3):425-427.

59. Rizza SA, Nehra V, Temesgen Z. Sofosbuvir/ledipasvir fixed-dose combination for treatment of chronic hepatitis $\mathrm{C}$ virus infection in children. Drugs Today. 2017;53(8):447-451.

60. Murray KF, Balistreri W, Bansal S, et al. Ledipasvir/sofosbuvir +/ribavirin for 12 or 24 weeks is safe and effective in children 6-11 years old with chronic hepatitis $\mathrm{C}$ infection. 52nd Annual Meeting of the European Association for the Study of the Liver (EASL). April 19-23, 2017; Amsterdam.
61. Miller MM. Sofosbuvir-velpatasvir: a single-tablet treatment for hepatitis C infection of all genotypes. Am J Health Syst Pharm. 2017;74(14):1045-1052.

62. Sofosbuvir/Velpatasvir in adolescents and children with chronic $\mathrm{HCV}$ infection. Available from: https://clinicaltrials.gov/ct2/show/ NCT03022981. Accessed June 3, 2018.

63. Carrion AF, Martin P. Glecaprevir + pibrentasvir for treatment of hepatitis C. Expert Opin Pharmacother. 2018;19(4):413-419.

64. Abutaleb A, Kottilil S, Wilson E. Glecaprevir/pibrentasvir expands reach while reducing cost and duration of hepatitis $\mathrm{C}$ virus therapy. Hepatol Int. 2018;12(3):214-222.

65. A study to evaluate the pharmacokinetics, safety, and efficacy of glecaprevir/pibrentasvir in pediatric subjects with genotypes 1-6 chronic hepatitis $\mathrm{C}$ virus (HCV) infection (DORA). Available from: https:// clinicaltrials.gov/ct2/show/NCT03067129. Accessed June 3, 2018.

66. Huysentruyt K, Stephenne X, Varma S, et al. Sofosbuvir/ledipasvir and ribavirin tolerability and efficacy in pediatric liver transplant recipients. Liver Transpl. 2017;23(4):552-553.

67. Psaros Einberg A, Fischler B. Successful treatment of paediatric hepatitis $\mathrm{C}$ with direct acting antivirals in select cases. Paper presented at: ESPGHAN 50th Annual Meeting 2017; Prague.
Adolescent Health, Medicine and Therapeutics

\section{Publish your work in this journal}

Adolescent Health, Medicine and Therapeutics is an international, peer-reviewed, open access journal focusing on health, pathology, and treatment issues specific to the adolescent age group. All aspects of health maintenance, preventative measures and disease treatment interventions are addressed within the journal and practitioners from all disciplines are
Submit your manuscript here: http://www.dovepress.com/adolescent-health-medicine-and-therapeutics-journal
Dovepress

invited to submit their work as well as healthcare researchers and patient support groups. This journal is included in PubMed. The manuscript management system is completely online and includes a very quick and fair peer-review system. Visit http://www.dovepress.com/testimonials. $\mathrm{php}$ to read real quotes from published authors. 